\title{
АНАЛИЗ ТИПОВ ПИЩЕВОГО ПОВЕДЕНИЯ И ОСОБЕННОСТЕЙ РЕЖИМА ПИТАНИЯ У ДЕВУШЕК И ИХ ОБЕСПОКОЕННОСТИ ПО ПОВОДУ НАБОРА ИЗБЫТОЧНОГО ВЕСА (НА МАТЕРИАЛЕ ИССЛЕДОВАНИЯ СТУДЕНТОВ ПЕРВОГО КУРСА)
}

\author{
Чеснокова Наталья Владимировна \\ магистрант \\ Научный руководитель: Абросимова Екатерина Анатольевна \\ к.П.н., доцент \\ ФГБОУ ВО «Челябинский государственный университет»
}

Аннотация: В статье кратко формулируются характеристики типов пищевого поведения, обосновывается актуальность изучения пищевого поведения у девушек, а также сообщается о результатах эмпирического исследования типов пищевого поведения (ограничительного, эмоциогенного и экстернального), проведенного с помощью опросника DEBQ на материале исследования 60 девушек студенток первого курса ВУЗа, проведенного автором. По результатам исследования установлено, что у большинства (78,3\%) девушек выявлены признаки нарушений пищевого поведения.

Ключевые слова: пищевое поведение, ограничительное пищевое поведение, эмоциогенное пищевое поведение, экстернальное пищевое поведение, нарушения пищевого поведения, голландский опросник пищевого поведения (DEBQ), DEBQ, индекс массы тела, девушки, студенты.

\section{ANALYSIS OF EATING BEHAVIOR AND FEATURES OF DIET IN GIRLS AND THEIR CONCERN ABOUT GETTING OVERWEIGHT (BY THE MATERIAL OF THE RESEARCH OF FIRST-YEAR STUDENTS)}

\section{Chesnokova Natalya Vladimirovna}

\begin{abstract}
The article briefly formulates the characteristics of the types of eating behavior, substantiates the relevance of studying eating behavior in girls, and also reports on the results of an empirical study of the types of eating behavior (restrictive, emotional and external), conducted using the DEBQ questionnaire on the material of a study of 60 girls, first-year university students, conducted by the
\end{abstract}


author. According to the results of the study, it was found that the majority of $78.3 \%$ of girls showed signs of eating disorders.

Key words: eating behavior, restrictive eating behavior, emotional eating behavior, external eating behavior, eating disorders, Dutch Eating Behavior Questionnaire (DEBQ), DEBQ, body mass index, girls, students.

По данным исследований в большинстве экономически развитых странах мира прослеживается отчетливая тенденция к увеличению числа лиц с нарушениями пищевого поведения, известных, в том числе, достаточно тяжелыми психическими и соматическими последствиями.

Нарушение пищевого поведения, являясь следствием многофакторного воздействия, препятствует гармоничному и эффективному развитию личности на всех этапах возрастного развития, становится барьером в эффективной личностной самореализации.

В то же время в популяции нарушения пищевого поведения по ограничительному, эмоциогенному и экстернальному типу встречается гораздо чаще, чем клинически диагностируемые расстройства «нервная анорексия» или «нервная булимия», при этом они также существенно влияют на качество жизни, состояние соматического и психического здоровья и психологическое благополучие людей.

Следует отметить, что значение периода юности на текущий момент развития общества существенно возрастает, так как именно в течение юношеского периода жизни формируется личность юношей и девушек. Молодые люди решают вопросы реализации себя в личной, профессиональной и социальной сферах жизни.

Изучение типов пищевого поведения и его нарушений у девушек видятся актуальными и значимыми, так как именно юношеский возраст ознаменован становлением процессов их самоопределения, их особенностями психологического развития в период юности, а именно их эмоциональной неустойчивостью, повышенной ранимостью, чувствительностью, колебанием самооценки. В этот период ими особенно болезненно воспринимаются также их внешность, и в частности фигура и вес.

С целью исследования типов пищевого поведения у девушек весной 2021 года в городе Челябинске было проведено исследование на базе Федерального государственного бюджетного образовательного учреждения высшего образования «Челябинский государственный университет», в 
котором приняли участие девушки - студенты первого курса очной формы обучения в количестве 60 человек.

Целью исследования стало выявление типов пищевого поведения у девушек. Объектом исследования явились типы пищевого поведения.

Под пищевым поведением понимается «ценностное отношение к пище и ее приему, стереотип питания в обыденных условиях и в ситуации стресса, ориентация на образ собственного тела и деятельность по его формированию». Пищевое поведение оценивается как гармоничное (адекватное) или девиантное (отклоняющееся) в зависимости от множества параметров, в частности от места, которое занимает процесс приема пищи в иерархии ценностей человека, от количественных и качественных показателей питания от эстетики и т.д. [1, с. 382].

Согласно мнению Покровского А.А. самой простой формой пищевого поведения является прием пищи с целью удовлетворения потребности в питательных веществах, когда еда является средством поддержания энергетического и пластического равновесия [2].

Пищевая потребность у человека предстает в более сложном виде, являясь по мнению Савенкова Ю.И. средством: разрядки психоэмоционального напряжения; чувственного наслаждения, выступающего как самоцель; общения, когда еда связана с пребыванием в коллективе; самоутверждения, когда первостепенную роль играют представления о престижности пищи и о соответствующей «солидной» внешности; поддержания определенных ритуалов или привычек (религиозные, национальные, семейные традиции); компенсации неудовлетворенных потребностей (потребность в общении, родительской заботе и т. д.); награды или поощрения за счет вкусовых качеств пищи; удовлетворения эстетической потребности [по 3].

Пищевое поведение определяют не только потребности, но и полученные в прошлом знания, стратегии мышления и поведения.

Ю.Л. Савинкова исследовала пищевое поведение и пишет о трех стратегиях аддиктивного пищевого поведения: эмоциогенном, ограничительном и экстернальном [4].

Эмоциогенное пищевое поведение наблюдается под воздействием стресса или эмоционального дискомфорта. Распространенная реакция на такие неприятные эмоции и состояния, как гнев, страх и тревога - потеря аппетита, но некоторые люди, напротив, реагируют на это чрезмерным 
потреблением пищи. Тревожность, раздражительность, плохое настроение, чувство одиночество у людей с эмоциогенным пищевым поведением может стать причиной приема излишней пищи.

Экстернальное пищевое поведение связано с повышенной чувствительностью к внешним стимулам потребления пищи: человек ест в ответ не на внутренние стимулы (уровень глюкозы и свободных жирных кислот в крови, пустой желудок и т.д.), а на внешние (обонятельные внешние стимулы (вид, запах еды), витрина продуктового магазина, хорошо накрытый стол, вид человека, принимающего пищу, реклама пищевых продуктов и т.д.)). Здесь играют роль и другие факторы: доступность пищи, интенсивность метаболических процессов, уровень самоконтроля [5].

Таким образом, человек с экстернальным пищевым поведением принимает пищу по принципу «вижу - ем». Именно эта особенность лежит в основе переедания «за компанию», перекусов на улице, избыточного приема пищи в гостях, покупки излишнего количества продуктов.

Ограничительное пищевое поведение характеризуется специальными усилиями, направленными на достижение или поддержание желаемого веса соблюдением диеты. Люди, ограничивающие себя в питании, игнорируют внутренние сигналы голода (или жажды) и придерживаются низкокалорийного режима питания с целью потери веса. Ограничительное пищевое поведение может возникнуть на фоне диетотерапии. Соблюдение чрезмерно строгой диеты без явной в плане здоровья необходимости, которую невозможно соблюдать долгое время, достаточно быстро сменяется периодами выраженного переедания.

Для определения типа пищевого поведения в российской и мировой психодиагностике пищевого поведения используется методика «Голландский опросник пищевого поведения (DEBQ)». Целью создания данного опросника было получение простого и валидизированного инструмента для качественной и количественной оценки расстройств пищевого поведения, связанных с перееданием и сопровождающим его ожирением, и дифференцированной выработки стратегии клинической работы с пациентами.

В ходе исследования для девушек был применен Голландский опросник пищевого поведения (Dutch Eating Behavior Questionnaire, DEBQ) в адаптации Минабутдинова Ш.Р. (1996). С его помощью выявляются типы пищевого поведения по трем шкалам: ограничительный, эмоциогенный и экстернальный. Нормальными считаются следующие значения по шкалам 
ограничительного, эмоциогенного и экстернального пищевого поведения: 2,4; 1,8 и 2,7 балла соответственно. Если значения по шкалам выше нормальных значений, можно сделать вывод о наличии выраженного типа пищевого поведения, то есть его отклонения от пищевого поведения в норме.

По результатам исследования, нормальное пищевое поведение (без превышений нормы по какой-либо шкале, то есть без выявленных тенденций к ограничительному, эмоциогенному и экстернальному типам нарушений пищевого поведения) выявлено у 13 девушек, что составляет только 21,7 \% всех испытуемых. У большинства же девушек (78,3\%) выявлены нарушения в чистом виде по ограничительному типу (у $5 \%$ ), эмоциогенному (у $1,7 \%$ ), экстернальному (13,3\%), а также по смешенному типу (у 58,3\%), когда значения выше среднего выявлены по двум или всем трем шкалам (табл. 1).

Таблица 1

Распределение вариантов пищевого поведения среди девушек-студенток первого курса по методике «Голландский опросник пищевого поведения» (по количеству и в \% испытуемых)

\begin{tabular}{|l|c|c|}
\hline \multicolumn{1}{|c|}{ Тип пищевого поведения } & $\begin{array}{c}\text { Количество } \\
\text { человек }\end{array}$ & $\begin{array}{c}\text { \% от общего } \\
\text { количества } \\
\text { испытуемых }\end{array}$ \\
\hline Нормальное & 13 & 21,7 \\
\hline Ограничительное & 3 & 5,0 \\
\hline Эмоциогенное & 1 & 1,7 \\
\hline Экстернальное & 8 & 13,3 \\
\hline Ограничительное + эмоциогенное & 4 & 6,7 \\
\hline Ограничительное + экстернальное & 2 & 3,3 \\
\hline Эмоциогенное + экстернальное & 20 & 33,3 \\
\hline Ограничительное + эмоциогенное + экстернальное & 9 & 15,0 \\
\hline
\end{tabular}

Это свидетельствует о наличии выраженного типа пищевого поведения, а именно отклонения от нормального пищевого поведения, и, следовательно, о возможном риске развития в будущем ожирения и/или формирования расстройств пищевого поведения, если девушки не будут уделять своему пищевому поведению и процессам приема пищи достаточного внимания и предпринимать меры коррекции пищевого поведения.

Дополнительно к опроснику DEBQ девушкам в ходе исследования было предложено ответить на несколько вопросов в анкете, касающихся других аспектов пищевого поведения, а также о своем весе: 
1. Ваш рост в см

2. Ваш вес в кг

3. Беспокоит ли Вас вопрос набора веса или лишнего веса?

4. Знаете ли Вы свою среднюю калорийность пищи, потребляемой за сутки?

5. Регулярно ли Вы принимаете пищу? Обычно в одно и то же время?

6. Перекусываете ли Вы между основными приемами пищи?

На основании данных о весе и росте для обследуемых был рассчитан индекс массы тела (ИМТ).

В результате исследования установлено, что недостаточную (дефицит) массу тела (которая соответствует показателям ИМТ в соответствии с рекомендациями ВОЗ в диапазоне от 16 до 18,5) имеют 14 девушек или 23,3 $\%$ всех обследуемых; нормальную массу тела (которая соответствует показателям ИМТ в соответствии с рекомендациями ВО3 в диапазоне от 18,5 до 25) имеют 42 девушки или 70\% от всех обследуемых; избыточную массу тела (предожирение) (которая соответствует показателям ИМТ в соответствии с рекомендациями ВОЗ в диапазоне от 25 до 30) имеют 2 девушки или 3,3 \% всех обследуемых; ожирение 1 степени (которое соответствует показателям ИМТ в соответствии с рекомендациями ВО3 в диапазоне от 30 до 35) имеет 1 девушка или $1,7 \%$ всех обследуемых; ожирение 2 степени (которое соответствует показателям ИМТ в соответствии с рекомендациями ВОЗ в диапазоне от 35 до 40) имеет 1 девушка или 1,7\% всех обследуемых. Данные результаты свидетельствуют, что в большинстве своем девушки имеют нормальную массу тела.

Распределение ИМТ по вариантам пищевого поведения среди девушекстуденток первого курса представлены в таблице 2.

\section{Таблица 2}

Распределение ИМТ по вариантам пищевого поведения среди девушек студенток первого курса (с данными количества и \% испытуемых)

\begin{tabular}{|l|c|c|c|c|c|}
\hline $\begin{array}{c}\text { Тип пищевого } \\
\text { поведения }\end{array}$ & $\begin{array}{c}\text { Дефицит } \\
\text { массы } \\
\text { тела }\end{array}$ & $\begin{array}{c}\text { Нормальная } \\
\text { масса тела }\end{array}$ & $\begin{array}{c}\text { Избыточная } \\
\text { масса тела }\end{array}$ & $\begin{array}{c}\text { Средний } \\
\text { ИМТ }\end{array}$ & $\begin{array}{c}\text { \% от } \\
\text { общего } \\
\text { количества } \\
\text { испытуемых }\end{array}$ \\
\hline Нормальное & $3(23 \%)$ & $8(62 \%)$ & $2(15 \%)$ & 20,9 & 21,7 \\
\hline Ограничительное & 0 & $1(100 \%)$ & 0 & 21 & 5,0 \\
\hline Эмоциогенное & 0 & $1(100 \%)$ & 0 & 18,7 & 1,7 \\
\hline
\end{tabular}


Продолжение таблицы 2

\begin{tabular}{|lr|c|c|c|c|c|}
\hline Экстернальное & $1(12,5 \%)$ & $7(87,5 \%)$ & 0 & 19,6 & 13,3 \\
\hline $\begin{array}{l}\text { Ограничительное } \\
\text { эмоциогенное }\end{array}$ & + & $2(50 \%)$ & $2(50 \%)$ & 0 & 19,2 & 6,7 \\
\hline $\begin{array}{l}\text { Ограничительное } \\
\text { экстернальное }\end{array}$ & + & 0 & $1(50 \%)$ & $1(50 \%)$ & 24,4 & 3,3 \\
\hline $\begin{array}{l}\text { Эмоциогенное } \\
\text { экстернальное }\end{array}$ & $4(20 \%)$ & $15(75 \%)$ & $1(5 \%)$ & 21,1 & 33,3 \\
\hline $\begin{array}{l}\text { Ограничительное } \\
\text { эмоциогенное } \\
\text { экстернальное }\end{array}$ & + & $3(33,3 \%)$ & $5(66,7 \%)$ & 0 & 21 & 15,0 \\
\hline
\end{tabular}

На вопрос «Беспокоит ли Вас вопрос набора веса или лишнего веса?» получены ответы: «да» от 39 девушек (65\% обследуемых) и «нет» от 21 девушки (35\% обследуемых).

На вопрос «Знаете ли Вы свою среднюю калорийность пищи, потребляемой за сутки?» получены ответы: «нет» от 42 девушек (70\% обследуемых), «да» от 18 девушек (30\% обследуемых).

Интересен то факт, что 65\% девушек беспокоит вопрос набора веса или лишнего веса, но при этом $70 \%$ девушек не знают свою среднюю калорийность пищи, потребляемой за сутки. Из этого можно предположить, что, возможно, они не следят за потребляемой калорийностью (то есть не уделяют этому своего внимания по каким-то причинам) либо не знают, как контролировать процесс набора веса с помощью базового принципа баланса потребляемой с пищей энергии и расходования энергии в процессе жизнедеятельности и поэтому не следят за этим.

На вопрос «Регулярно ли Вы принимаете пищу? Обычно в одно и то же время?» получены ответы: «нет» от 42 девушек (70\%), «да» от 18 девушек $(30 \%)$.

На вопрос «Перекусываете ли Вы между основными приемами пищи?» получены ответы: «да» от 49 девушек (82\% обследуемых) и «нет» от 11 девушек (18\% обследуемых).

Это свидетельствует о том, что большинство девушек не имеют привычки регулярно питаться в одно и то же время и имеют привычку перекусывать, а значит они подвержены риску ситуативного приема пищи под влиянием других факторов кроме голода, например, под влиянием эмоций, внешних признаков пищи и социального фактора (еда за компанию и подобные), то есть могут есть больше, чем требуется их организму для 
пополнения требуемой энергии и поступления необходимых питательных веществ, что в свою очередь может привести к накоплению избыточного веса.

По типам пищевого поведения распределение ответов на указанные вопросы представлены в таблице 3 .

Таблица 3

Распределение ответов на вопросы анкеты по вариантам пищевого поведения среди девушек-студенток первого курса

(с данными количества и \% испытуемых)

\begin{tabular}{|c|c|c|c|c|}
\hline $\begin{array}{c}\text { Тип пищевого } \\
\text { поведения }\end{array}$ & $\begin{array}{c}\text { Беспокоит ли } \\
\text { Вас вопрос } \\
\text { набора веса или } \\
\text { лишнего веса ? }\end{array}$ & $\begin{array}{c}\text { Знаете ли Вы } \\
\text { свою среднюю } \\
\text { калорийность } \\
\text { пищи, } \\
\text { потребляемой } \\
\text { за сутки? }\end{array}$ & $\begin{array}{c}\text { Регулярно ли Вы } \\
\text { принимаете } \\
\text { пищу? Обычно в } \\
\text { одно и то же } \\
\text { время? }\end{array}$ & $\begin{array}{c}\text { Перекусываете } \\
\text { ли Вы между } \\
\text { основными } \\
\text { приемами пищи? }\end{array}$ \\
\hline Нормальное & $\begin{array}{l}\text { «а » - 5 (39\%) } \\
\text { «Нет»- } 8 \text { (61\%) }\end{array}$ & $\begin{array}{c}\text { «Да }-3(23 \%) \\
\ll Н е т »-10 \\
(77 \%)\end{array}$ & $\begin{array}{c}\text { «а } »-4(30,7 \%) \\
« \text { Нет»- } 9 \\
(96,3 \%) \\
\end{array}$ & $\begin{array}{l}\ll Д а »-8(61 \%) \\
\text { «Нет»- } 5(39 \%)\end{array}$ \\
\hline Ограничительное & «Да»- 3 (100\%) & $\begin{array}{l}\text { «а » - } 2 \text { (67\%) } \\
\text { «Нет» - } 1(33 \%)\end{array}$ & «Нет»- $3(100 \%)$ & «Да»- 3 (100\%) \\
\hline Эмоциогенное & $\begin{array}{c}\text { «ет» }-1 \\
(100 \%) \\
\end{array}$ & $\begin{array}{c}\text { «Нет» - } 1 \\
(100 \%) \\
\end{array}$ & «Нет»- $1(100 \%)$ & «Да»- 1 (100\%) \\
\hline Экстернальное & $\begin{array}{l}\text { «а » - } 4 \text { (50\%) } \\
\text { «Нет» - } 4 \text { (50\%) }\end{array}$ & $\begin{array}{c}\text { «а }-1(12,5 \%) \\
\text { «Нет»-7 } \\
(87,5 \%)\end{array}$ & $\begin{array}{l}\text { «Да» - } 2(25 \%) \\
\text { «Нет»- } 6(75 \%)\end{array}$ & «Да»- 8 (100\%) \\
\hline $\begin{array}{l}\text { Ограничительное } \\
+ \text { эмоциогенное }\end{array}$ & «Да»- 4 (100\%) & $\begin{array}{l}\text { «Да»- } 1(25 \%) \\
\text { «Нет»- } 3(75 \%)\end{array}$ & $\begin{array}{l}\text { «Да»- } 1(25 \%) \\
\text { «ет» - 3 (75\%) }\end{array}$ & «Да»-4 (100\%) \\
\hline $\begin{array}{l}\text { Ограничительное } \\
+ \text { экстернальное }\end{array}$ & «Да»- 2 (100\%) & $\begin{array}{l}\text { «а »- } 1(50 \%) \\
\text { «Нет»- } 1(50 \%)\end{array}$ & «Нет»- $2(100 \%)$ & «Да»- 2 (100\%) \\
\hline $\begin{array}{l}\text { Эмоциогенное + } \\
\text { экстернальное }\end{array}$ & $\begin{array}{l}\text { «Да» - } 13(65 \%) \\
\text { «Нет» - } 7(35 \%)\end{array}$ & $\begin{array}{c}\text { «Да»- } 5(25 \%) \\
\text { «Нет»- } 15 \\
(75 \%) \\
\end{array}$ & $\begin{array}{l}« Д а »-8(40 \%) \\
« Н е т »-12(60 \%)\end{array}$ & $\begin{array}{c}\text { «Да }-19(95 \%) \\
\text { «ет» - } 1(5 \%)\end{array}$ \\
\hline $\begin{array}{l}\text { Ограничительное } \\
+\quad \text { эмоциогенное } \\
+ \text { экстернальное } \\
\end{array}$ & «Да»- $9(100 \%)$ & $\begin{array}{c}\text { «ет» - } 2(22 \%) \\
\text { «Да - } 7(78 \%)\end{array}$ & $\begin{array}{l}\text { «Да }-3(33 \%) \\
« Н е т »-6(67 \%)\end{array}$ & $\begin{array}{l}\text { «а »- } 4 \text { (44\%) } \\
\text { «нет»- } 5(56 \%)\end{array}$ \\
\hline
\end{tabular}

Относительно беспокойства по поводу лишнего веса и набора веса получены данные, что наиболее обеспокоены этим оказались девушки со 
смешенным эмоциогенно-эктернальным типом пищевого поведения - 13 девушек или 22\% всех обследуемых, наименее обеспокоены вопросами веса оказались девушки с нормальным пищевым поведением - 8 девушек или $13 \%$ всех обследуемых.

Таким образом, по результатам исследования установлено, что у большинства девушек студенток первого курса ФГБОУ ВО «ЧелГУ» (78,3\% испытуемых) выявлены признаки нарушений пищевого поведения.

При нарушениях пищевого поведения повышаются риски возникновения расстройств пищевого поведения и развития ожирения. В частности, при ограничительном типе пищевого поведения имеется некоторый риск развития расстройства пищевого поведения по типу анорексии.

При эмоциогенном типе пищевого поведения повышается риск развития расстройства пищевого поведения в виде психогенного или компульсивного (приступообразного) переедания и нервной булимии, а также накопления избыточного веса и развития ожирения, если человек не научится регулировать свое эмоциональное состояние без помощи еды и не будет допускать переизбытка поступающей с пищей энергии.

При экстернальном типе пищевого поведения имеется риск накопления избыточного веса и развития ожирения, если человек не будет уделять достаточного внимания и осознанности к принятию пищи и не будет допускать переизбытка поступающей с пищей энергии.

Полученные данные могут быть использованы для более объективного анализа пищевого поведения в норме и в отклонении (патологии), а также для совершенствования программ и методик профилактики,тпсихологической коррекции и психотерапии нарушений и расстройств пищевого поведения и связанных с ними заболеваний.

\section{Список литературы}

1. Менделевич, В.Д. Клиническая и медицинская психология [Текст]/ В.Д, Менделевич.- М.: МедПресс-информ, 2005. - 896 с.

2. Покровский, А. А. Роль биохимии в развитии науки о питании [Текст] / А.А. Покровский. - Москва : Наука, 1974. - 127 с.

3. Малкина-Пых, И. Г. Терапия пищевого поведения [Текст] / И. Г. Малкина-Пых. - М.: Эксмо, 2007. - 1040 с. 
4. Савинкова, Ю.Л. Психологические особенности женщин с проблемами веса [Электронный ресурс]: автореф. дис. ... канд. психол. наук. СПб., 2005. - 26 с. - Режим доступа: URL: http://nauka-pedagogika.com/viewer/ 126236/a?\#?page $=26(01.02 .2022)$

5. Леонова, Е.Н. Социально-психологические типы пищевого поведения [Электронный ресурс] / Е.Н. Леонова // Вестник Удмуртского университета. Серия: Философия. Психология. Педагогика - Ижевск : Удмуртский гос. ун-т, 2017. - Т. 2, вып. 2. - с. 174-181- Режим доступа: URL: https://cyberleninka.ru/article/n/sotsialno-psihologicheskie-tipy-pischevogopovedeniya (01.02.2022)

6. Донцов, Д. А. Возрастная психология и психология развития личности в макропериоде детства, в отрочестве и юности [Электронный peсурс]: учебное пособие / Д. А. Донцов, М. В. Донцова. - 2-е изд., стер. Москва : ФЛИНТА, 2019. - 308 с. - Режим доступа: электронная библиотечная система «Университетская библиотека ONLINE» URL: https://biblioclub.ru/index.php?page=book\&id=603182 (дата обращения: 12.01.2022).)

7. Савинкова, Ю.Л. Психологические особенности женщин с проблемами веса [Электронный ресурс]: автореф. дис. ... канд. психол. наук. СПб., 2005. - 26 с. - Режим доступа: URL: http://naukapedagogika.com/viewer/126236/a?\#?page=26 (дата обращения: 12.01.2022).

8. Федорова, И. И. Клинико-динамический и психотерапевтический аспекты нарушений пищевого поведения [Электронный ресурс]: автореф. дис. ... кандидата мед. наук. - Томск, 2007. - 26 с. - Режим доступа: URL: https://dlib.rsl.ru/viewer/01003177296\#?page=1 (дата обращения: 12.01.2022).

9. Филиппова, С.А. Феномен неудовлетворенности собственным телом в юношеском возрасте: психологические причины и возможности коррекции [Электронный ресурс] / С.А. Филиппова // Психолог. - 2017. - №4.- С. 21-31. Режим доступа: URL: https://cyberleninka.ru/article/n/fenomen-neudo vletvorennosti-sobstvennym-telom-v-yunosheskom-vozraste-psihologicheskie-pric hiny-i-vozmozhnosti-korrektsii (дата обращения: 12.01.2022).

(C) Н.В. Чеснокова, 2022 